\title{
The Effect of Procrastination on Multi-Drafting in a Web-Based Learning Content Management Environment
}

\author{
Miriam Sarid \\ Western Galilee College, \\ Israel \\ mirisarid@gmail.com
}

\author{
Yehuda Peled \\ Western Galilee College, \\ Ohalo College, Israel \\ ypeled@macam.ac.il
}

\begin{abstract}
During the 2003-2008 school years, a multi-drafting teaching method was tried and formalized in a rural college in Israel using the HighLearn MCL web-based environment. The aim of the current study was to determine the influence of procrastination and anxiety on students' attitudes toward multi-drafting teaching methods.

The research was based on three self-evident questionnaires: (1) Multi-drafting, (2) Procrastination and (3) Trait anxiety.

The results indicate that there are four variables that influence students' attitudes toward multidrafting: (1) gender: female attitude toward multi-drafting is more positive than that of males; (2) trait anxiety: the more anxious the student is, the lower the attitude toward and implementation of multi-drafting; (3) year at the college: the more advanced the year of studies, the lower the attitudes are toward multi-drafting; (4) procrastination: the higher level of procrastination is, the lower level of implementation of multi-drafting is. The implication of these findings is that although technology facilitates teaching that promotes meaningful learning, personal traits have not changed.
\end{abstract}

Keywords: multi-drafting; web-based learning content management; procrastination, anxiety; meaningful learning.

\section{Introduction}

The traditional approach to assigning and evaluating written work at the undergraduate level focuses on the final product, the single copy of a written assignment that is handed in to the lecturer. The instructor typically acts as both editor and judge, rarely allowing students an opportu-

Material published as part of this publication, either on-line or in print, is copyrighted by the Informing Science Institute. Permission to make digital or paper copy of part or all of these works for personal or classroom use is granted without fee provided that the copies are not made or distributed for profit or commercial advantage AND that copies 1) bear this notice in full and 2) give the full citation on the first page. It is permissible to abstract these works so long as credit is given. To copy in all other cases or to republish or to post on a server or to redistribute to lists requires specific permission and payment of a fee. Contact Publisher@InformingScience.org to request redistribution permission. nity to rethink, rework, or expand on the paper based on feedback (Koffolt \& Holt, 1997). The centrality of feedback to student-writers is well documented within academic literacy literature (Benesch, 2000; Hyland \& Tse, 2004). Winnips (2000) relates feedback to different points in the learning experience and sees it as a tool for scaffolding learners toward more self-regulation. A very important skill for any instructor is

\section{Editor: Alex Koohang}

An earlier, shorter version of this paper was presented at the Chais conference 2010, in Raanana, Israel, and included in Y. Eshet-Alkalai, A. Caspi, S. Eden, N. Geri, \& Y. Yair (Eds.), Proceedings of the Chais conference on instructional technologies research 2010: Learning in the technological era. Raanana: The Open University of Israel. http://www.openu.ac.il/research center eng/conferences.html 
being able to give feedback to students on their performance (Russell, 1994). Giving feedback via a web-environment to a series of assignments seems to be a good response to some of the challenges described above. It has the advantage of flexibility; an instructor does not have to be in his or her office in order to support a student and can turn to student submissions and provide feedback wherever the instructor has access to a networked computer (Collis, De Boer \& Slotman, 2001). Using a Web-Based Learning Content Management Environment (LCM) enables the lecturer to supply constant feedback on the student's assignments through the multi-drafting teaching method.

During the 2003-2008 school years, a multi-drafting teaching method was tried and formalized in a rural college in Israel. The method offers the student the opportunity to submit a written assignment digitally as many times as needed during a defined time frame. Throughout that period, the assignment is graded and suggestions for improvement are offered by the lecturer, who in practice acts as a tutor. In this way the student can refine his work through a continuous dialogue with his lecturer. A digital portfolio (Bobak, 2004; Wiedmer, 1998) of the student's work is created along with the lecturer's remarks and suggestions.

The multi-drafting process uses the Britannica HighLearn web-based learning content management, which is a Hebrew-language, Web-based course-management tool that allows lecturers to develop and deliver academic courses via the Internet. HighLearn is password protected, thus students and lecturer log on with their real identity, allowing transparent information flow. It generates and displays the student's grading, thus enabling him or her to appreciate the improvement with each refined draft. The student writes the assignment using Microsoft Word, which allows a two-way feedback process, using the Track Changes and Comment functions, thus constructing the student's knowledge and understanding through continuous formative evaluation for every given assignment. The process described here allows the student to reject or accept changes and improvements offered by the lecturer and, thus, promotes a continuous dialogue between them. On each assignment, the lecturer's assistance is offered through the multi-drafting technique, thereby providing the opportunity to refine the work. The incentive offered by the lecturer is maximum grading; furthermore, the students are assured that if their work is submitted in a timely manner, utilizing to the maximum the timeframe defined for the assignment, the drafting process will continue until satisfactory results are achieved. This method is also beneficial for the lecturer, since it gives him or her assurance that it is undoubtedly the student's original work (Barrett, 2007) and that no plagiarism is involved.

There is little or no evidence of research on multi-drafting as a teaching technique in subjects other than English as a foreign language and writing classes. Multi-drafting is used by lecturers of writing and language skills in order to enhance students' learning and improve their writing proficiency (Yang, 2006), and it is most beneficial if the student has time to revise and send the draft to the lecturer (Chryssafidou \& Sharples, 2002) in order to receive meaningful feedback.

With the advent of networking and multimedia technologies, the emphasis on technology-based education of all kinds for the support of student learning has been a focus of contemporary education (Yu, Liu, \& Chan, 2005). Most universities worldwide are becoming distance education providers through adopting web-based learning and teaching via the introduction of learning management systems. This gives them the means to open their courses for both on- and off-campus students (Samarawickrema \& Stacey, 2007), utilizing attributes of learner control and instant and personalized feedback (Yu et al., 2005). The difficulty in enhancing meaningful learning (Novak, 2002) in undergraduate academic literacy courses in which the students acquire their academic learning skills (Mateos, Villalon, De Dios, \& Martin, 2007) led us to seek ways to enhance meaningful learning through integrating Information Technology (IT) into teaching (Loertscher, 2006). The use of IT in teaching enabled the integration of formative evaluation as part of the teaching process. In a previous study Peled and Sarid (2010) examined what happens when students are 
offered the opportunity to submit a written assignment digitally in an LMS environment as many times as needed during a defined timeframe. Throughout that period the assignment is graded and suggestions for improvement are offered by the lecturer. They found that there is a direct, positive correlation between the number of submissions and the student's grade; the more drafts for revision the higher the score achieved. Those who did take full advantage of the multi-drafting mechanism (26\%) (three submissions and higher), may have experienced a state of Flow, which is a feeling of energized focus: an intrinsically enjoyable condition that is accompanied by a number of positive experiential characteristics, including feelings of control and full involvement, success and enjoyment of the process of the activity (Csíkszentmihályi, 1991; Lee, 2005). Consequently, we assume that students who experienced the Flow state are not likely to put off their learning tasks until later (Lee, 2005) as they experience a positive feeling toward their work

A significant proportion of the students (42\%) did not take advantage of the process offered while $32 \%$ did take advantage but with only two submissions per assignment. The disappointment could neither be avoided nor denied: a major proportion of students did not utilize to the full extent the timeframe designated for the assignment. Based on Ellis and Knaus (1977), Rothblum, Solomon, and Murakami (1986) and Schroeder (2002), all of whom claim that the majority of college students procrastinate to some extent, it is reasonable to assume that these students, too, are to some extent procrastinators (Lee, 2005; Schroeder, 2002). This assumption is strengthened by the fact that most of the assignments which received failing grades were submitted on the last day allowed (i.e., a single submission).

Procrastination has been defined as the tendency to delay initiation or completion of important tasks (Ferrari, Johnson \& McCown, 1995; Lay, 1986), a lack of self-regulating performance, putting off work that could be under one's control (Tuckman,1991), or to delay tasks to the point of discomfort (Solomon \& Rothblum, 1984). Most students procrastinate on some academic tasks to some degree, and about a quarter report that they frequently procrastinate to a degree that causes them stress and/or lower academic performance (Ferrari et al., 1995; Hill, Hill, Chalot \& Barrall, 1978; Solomon \& Rothblum, 1984). Ellis and Knaus (1977) claim that as many as $70 \%$ of the students procrastinate, while Solomon and Rothblum (1984) state that $50 \%$ of college students procrastinate at least half of the time and an additional $38 \%$ procrastinate occasionally. Schroeder (2002) reports that 55\% of students admit to being "serial procrastinators": they never catch up after putting off projects and are continually working against the clock to finish their papers.

There are various reasons for procrastinating. It is associated with poor time management and task evasion (Milgrim, Marshevsky \& Sadeh, 1995). It crosses gender and racial categories (Ferrari, Keane, Wolfe, \& Beck, 1998). Students are poor at time management and leave preparation of work until the date it is due. This practice forces students into completing the assignments quickly, which frequently results in superficial treatment of the subject matter (Thomson \& Falchikov 1998; Schroeder, 2002). There is little research into what causes a student to procrastinate. Day, Mensink, and O'Sullivan (2000) found that the most common patterns underlying academic procrastination appear to be a confident postponement of work while pursuing other, mainly social activities, or a low interest in academic work along with a disinclination to do it to please others.

Van Eerde (2003) writes that "procrastination is not necessarily dysfunctional" (p. 421), arguing that the outcome of procrastination may only lead to time pressure and that for easy, boring, or routine tasks, time pressure may simply create a challenge and may lead to finishing a task faster. There are other positive consequences of procrastination. It has been shown to function as a temporary relief from stress and as a strategic effort to temporarily improve a bad mood (Tice, Bratslavsky, \& Banmeister, 2001). 
As the correlation between procrastination and multi-drafting is not clear-cut, we conducted further research in order to determine the influence of procrastination and anxiety on students' attitudes toward multi-drafting teaching methods.

Anxiety is a frequent response to stressful evaluation situations and may be correlated with the performance being evaluated (Edwards \& Trimble, 1992). It has been associated with procrastination (Endler, Kantor \& Parker, 1994; Ferrari et al. 1998; Haycock, McCarthy \& Skay, 1998) and task avoidance (Endler et al., 1994). A distinction between state and trait anxiety has become commonplace (Spielberger, 1983). State anxiety is defined as an unpleasant emotional arousal in the face of threatening demands or dangers. A cognitive appraisal of threat is a prerequisite for the experience of this emotion (Lazarus, 1991). Trait anxiety, on the other hand, reflects the existence of stable individual differences in the tendency to respond with state anxiety in the anticipation of threatening situations.

Our initial findings (Peled \& Sarid, 2010) show that as the deadline approaches, the frequency of assignment submissions rises, meaning that the majority of the students delay their submissions despite the probability of achieving higher grades if the assignment is submitted as soon as possible using the multi-drafting technique.

Some research indicates no significant gender differences in the incidence of procrastination (e.g., Effert \& Ferrari, 1989; Haycock et al., 1998; Rothblum et al., 1986; Solomon \& Rothblum, 1984), whereas other research suggests that women are at greater risk than men (e.g., Paludi \& Frankell-Hauser, 1986). Furthermore, women may experience greater levels of anxiety associated with procrastination (Rothblum et al., 1986). Uzun Özer, Demir, and Ferrari (2009) and Masson et al. (2004) report that male students procrastinate more frequently on academic tasks than female students, with female students tackling the task as soon as possible.

As procrastination is associated with students' success and attitude toward learning (Schroeder, 2002) and test anxiety and writer's block associated with procrastination (Ferrari et al., 1998), we set out to pursue the effect of demographic characteristics, anxiety, and procrastination on students' decisions to utilize the multi-drafting mechanism offered to them.

\section{Method}

\section{Participants}

The sample consisted of 143 college students, $66 \%$ of them female. The mean age of the respondents was 31 years ( $\mathrm{SD}=8.8$ years). $66 \%$ of the students were freshmen, and another $34 \%$ were second and third year students.

\section{Procedure and Sampling}

The data collection was carried out in the classes where the students learn. All the students that were present in the class responded to the questionnaire and returned it to the researcher.

\section{Tools}

The research was based on three self-report questionnaires:

\section{Multi-drafting}

The multi-drafting questionnaire is a Likert multiple choice, 1-5 points scale questionnaire consisting of 23 items, dealing with attitudes toward multi-drafting in learning, in which a higher score represents a higher degree of agreement and a lower score represents a lower degree of agreement with multi-drafting as a method of learning. For example: "I submit the task as soon as 
it is published". The total score of multi-drafting is an average composed of all the items. The internal consistency measured in the current study by Cronbach alpha is $\alpha=0.91$.

\section{Procrastination}

The procrastination inventory was based on Tuckman (1991), which was translated into Hebrew and validated (by back translation). It consists of 16 Likert scale items, each of them ranked on a scale of one (lowest agreement) to five (highest agreement). The internal consistency of the procrastination scale was examined with a Cronbach coefficient of reliability and a high level of internal consistency was found $(\alpha=0.91)$. Each of the items of the procrastination inventory examines the level of procrastination that the respondent reports about, for example, "I delay making tough decisions", or "I needlessly delay finishing jobs, even when they are important". The scale includes three reversed items ("I always finish important jobs with time to spare"), and the higher the total score, the higher the level of procrastination.

\section{Trait anxiety}

The Spielberger State-Trait Anxiety Inventory (STAI) (Spielberger, Gorsuch \& Lushene, 1968) was used to measure respondent's anxiety. The STAI is an anxiety inventory commonly used in procrastination research. It consists of two 20 -item scales on a Likert score, the Trait scale and the State scale (each of them composed of 20 items). In the current research we used the trait anxiety inventory. The Trait scale is a measure of relatively stable individual differences in anxietyproneness or a tendency to perceive situations as threatening or dangerous. A higher score of anxiety represents a higher level of anxiety.

\section{Results}

In order to examine the effect of student's characteristics, anxiety, and procrastination on attitudes toward multi-drafting, a linear regression model was constructed. The predictors in the regression were gender, age, year of study at the college, trait anxiety and procrastination score, while the outcome measure was attitudes toward multi-drafting.

The regression results showed that the female respondents have a more positive attitude towards multi-drafting $(\beta=-.22, p<.01)$. The more advanced the year of studies, the lower the attitudes are toward multi-drafting $(\beta=-.19, p<.05)$. In addition, a higher level of anxiety as well as a higher level of procrastination were found to be related to lower attitudes and implementation of multi-drafting $(\beta=-.21, p<.01 ;(\beta=-.33, p<.001$, respectively). The whole regression model accounts for $32 \%$ of variance $\left(F_{(5,108)}=10.23, p<.001\right)$.

Additional regression was carried out with procrastination as a dependent measure and student's characteristics as predictors (gender, year of studies, age) and state anxiety as well.

The results highlighted that the more senior the student, the higher level of procrastination $(\beta=.19, p<.05)$. In addition it was found that the more the student is anxious, the more he or she is a procrastinator $(\beta=.32, p<.001)$ (see Table 1$)$. 
Table 1. Means, SDs' coefficients alpha and correlation coefficients for all variables

\begin{tabular}{|c|c|c|c|c|c|c|}
\hline & Mean & SD & $\begin{array}{l}\text { Cronbach } \\
\text { alpha }\end{array}$ & Anxiety & $\begin{array}{l}\text { Multi- } \\
\text { drafting }\end{array}$ & Year \\
\hline Procrastination & 2.17 & .63 & 0.91 & $0.30^{* *}$ & $-.46^{* \star}$ & .10 \\
\hline Anxiety & 2.41 & .75 & 0.94 & & $-.26^{* *}$ & $-.18^{*}$ \\
\hline Multi-drafting & 3.66 & .62 & 0.91 & & & $-.17^{*}$ \\
\hline $\begin{array}{l}\text { Student seniority } \\
\text { (year) }\end{array}$ & 1.57 & .90 & & & & \\
\hline
\end{tabular}

The whole regression model accounts for $14 \%$ of explained variance $\left(F_{(4,109)}=4.39, p<.01\right)$.

(For summary model of the results see Figure 1).

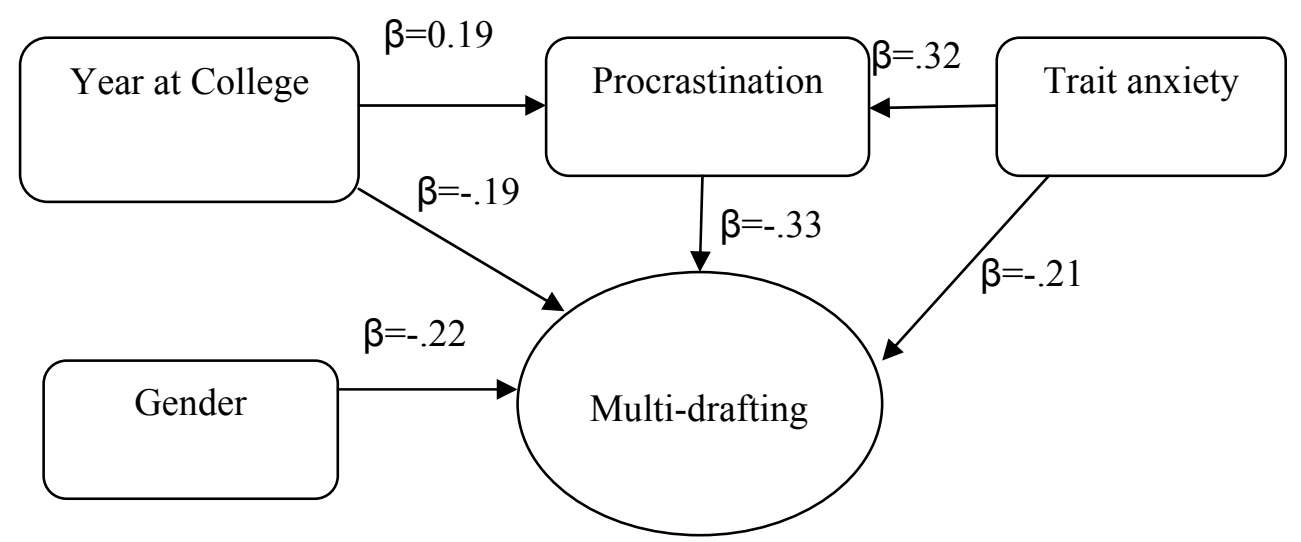

Figure 1: predicting multi-drafting attitudes by students' characteristics, procrastination, and anxiety

\section{Discussion}

Although the multi-drafting teaching method ought to encourage students to revise their work and improve it, since the incentive is a higher grade, in reality it is not so. As was found in previous research by Peled and Sarid (2010), only $26 \%$ of the students took full advantage of the opportunity to improve their work through lecturer feedback, while $42 \%$ of students submitted their work once and 32\% twice. Solomon and Rothblum (1984) state that $50 \%$ of college students procrastinate at least half of the time and an additional $38 \%$ procrastinate occasionally. This provided the basis for the assumption that the reason for not taking advantage of the multi-drafting might be procrastination. The way the students regard multi-drafting was found to be affected by four variables (see Figure 1): (1) gender; (2) year of study at the college (seniority); (3) procrastination, and (4) trait anxiety.

The results showed that anxiety and seniority at college have a direct and an indirect effect on multi-drafting. Anxiety has an effect on multi-drafting and on procrastination as well. The results indicate that a student with high level of anxiety tends to regard multi-drafting unfavorably, which relates to procrastination. There is a negative relationship between the willingness of a student to resubmit his work through the multi-drafting mechanism, and a positive correlation between trait anxiety and procrastination, which together means that students who tend to procrasti- 
nate have a higher anxiety score. We assume that anxiety affects students' willingness to rewrite their work and submit it on time. Procrastinating students have a lower preference for the multidrafting method, and anxious students also have lower preference for multi-drafting. As a result of the correlation between procrastination and anxiety, it is natural to assume that some proportion of procrastinators have a measure of trait anxiety and thus have lower attitudes toward multidrafting.

Haycock et al. (1998) found that procrastination was significantly and positively related to both state and trait anxiety $(\mathrm{r}=.31$ and .23 , respectively), but was not related to either age or sex, which correlates to our model (Figure 1).

First year students show a more positive attitude toward multi-drafting then second and third year students. Moreover the same is found in regard to procrastination. First year students procrastinate less then second and third year students. As third year students procrastinate more than first year students and procrastinators have a lower preference for multi-drafting, it can be assumed that student's year at college and procrastination have a cumulative effect on multi-drafting. There is a need to explain why third year students regard multi-drafting in a less positive light then first year students. It may be due to the fact that at this stage of their studies they are at the key point of survival in college. They are eager to complete their third year and receive their diploma. Many of the students carry with them past obligations, such as courses that have been left to the third year, failed courses which have to be retaken, and most especially there are the final research work - seminars (sometimes up to three of them) which have to be completed by the end of the third year. This means that the third year student is functioning under a cognitive overload and is pressed for time.

The current study found that female students have better attitudes towards the multi-drafting method of learning. Other studies regarding procrastination among men and women found that male students procrastinate more frequently than female students in academic tasks (Uzun Özer et al., 2009; Masson et al., 2004) while female students tackle the task as soon as possible.

Women's preference not to defer academic tasks and the higher level of procrastination among men correlate with the relationship in this research between procrastination and multi-drafting. Students who procrastinate have a low attitude towards multi-drafting. Since the men procrastinate more, their attitudes to multi-drafting are less positive.

Moon and Illingworth (2005) imply that in their attempts to understand academic procrastination, researchers have generally treated it as an immutable personality trait or disposition. As a result, they implicitly assume that academic procrastination is stable across tasks, contexts, and time. Overall, the results of various research suggest that procrastination is not a stable personality disposition, but is in fact a dynamic behavior that changes over time depending on the interaction of tasks and contexts. Our findings reveal a tendency to postpone submission of assignments until immediately prior to the submission deadline. Howell, Watson, Russell, Powell \& Buro (2006), in their study into the pattern and correlation of behavioral postponement of assignment submission, found a similar pattern. Moreover, their findings show an increasing rate of assignment submissions as the deadline approaches.

A general implication of this study is its support for considering procrastination as a behavioral effect, not a homogeneous trait, as the behavioral phenomena is procrastinating and avoiding resubmission of the drafts. Moreover there are other factors, such as anxiety and year at college, that are directly related to multi-drafting and procrastination, while gender influences the way students regard multi-drafting, independently of others factors. From the lecturer's point of view the outcome is procrastinating behavior, he cannot tell the source of the procrastination behavioral phenomena. 
What is particular about the present research findings is that notwithstanding the "prize" offered to students (multiple submissions with the chance to obtain higher grades) they do not make use of it. From this we can deduce that procrastination is not influenced by external factors. Procrastination is so built-in to the character of the procrastinator that no external factor will overcome it. Anxiety is an obstacle for a person and it expresses itself as procrastination, and we can view procrastination similarly to anxiety as a character feature.

\section{References}

Barrett, H. (2007). Researching electronic portfolios and learner engagement: The Reflect Initiative. Journal of Adolescent \& Adult Literacy, 50(6), 436-450.

Benesch, S. (2000) Critical English for academic purposes: Theory, politics and practice. Mahwah, NJ: Lawrence Erlbaum Associates.

Bobak, R. A. (2004). Electronic portfolios. Distance Learning, 1(6), 1-9.

Chryssafidou, E., \& Sharples, M. (2002). Computer-supported planning of essay argument structure. Proceedings of the 5th International Conference of Argumentation, Amsterdam, June 25-28, 2002. Retrieved January 9, 2009, from http://postgrad.eee.bham.ac.uk/chryse/Issa02.doc

Collis, B., De Boer, W., \& Slotman, K. (2001). Feedback for web-based assignments. Journal of Computer Assisted Learning, 17, 306-313.

Csíkszentmihályi, M. (1991). Flow: The psychology of optimal experience. Harper Collins, New York.

Day, V., Mensink, D., \& O'Sullivan, M. (2000). Patterns of academic procrastination. Journal of College Reading and Learning, 30(2), 120-134.

Edwards, J. M., \& Trimble, K. (1992). Anxiety, coping and academic performance. Anxiety, Stress \& Coping, 5(4), $337-350$.

Effert, B. R., \& Ferrari, J. R. (1989). Decisional procrastination: Examining personality correlates. Journal of Social Behavior and Personality, 4, 151-156.

Ellis, A., \& Knaus, W. J. (1977). Overcoming procrastination or how to think and act rationally in spite of life's inevitable hassles. New York, NY: Institute for Rational Living.

Endler, N. E., Kantor, L., \& Parker, J. D. A. (1994). State-trait coping, state-trait anxiety and academic performance. Personality and Individual Differences, 16(5), 663-670.

Ferrari, J. R., Johnson, J., \& McCown, W. G. (1995). Procrastination and task avoidance: Theory, research, and treatment. New York: Plenum Press.

Ferrari, J. R., Keane, S. M., Wolfe, R. N., \& Beck, B. L. (1998). The antecedents and consequences of academic excuse-making: Examining individual differences in procrastination. Assessment \& Evaluation in Higher Education, 39(2), 199-215.

Haycock, L. A., McCarthy, P., \& Skay, C. L. (1998). Procrastination in college students: The role of selfefficacy and anxiety. Journal of Counseling and Development, 76(3), 317-325.

Hill, M. B., Hill, D. A., Chalot, A. E., \& Barrall, J. F. (1978). A survey of college faculty and student procrastination. College Student Journal, 12, 256-262.

Howell, A. J., Watson, D. C., Powell, R. A., \& Buro, K. (2006). Academic procrastination: The pattern and correlates of behavioural postponement. Personality and Individual Differences, 40, 1519-1530.

Hyland, K., \& Tse, P. (2004). Metadiscourse in academic writing: A reappraisal. Applied Linguistics, 25(2), 156-177.

Koffolt, K., \& Holt, S. (1997). Using the 'writing process' with non-native users of English. New Directions for Teaching \& Learning, 70, 53-70. 
Lay, C. H. (1986). At last my research article on procrastination. Journal of Research in Personality, 20, 474-495.

Lazarus, R. S. (I 991). Emotion and adaptation. London: Oxford University Press.

Lee, E. (2005). The relationship of motivation and flow experience to academic procrastination in university students. The Journal of Genetic Psychology, 166(1), 5-15.

Loertscher, D. (2006). Teacher-librarian as technology leader. Teacher Librarian. 34(1), 45-53

Masson, A. M., Hoyois, P., Cadot, M., Nahama, V., Petit, F., \& Ansseau, M. (2004). Girls are more successful than boys at the university. Gender group differences in models integrating motivational and aggressive components correlated with Test-Anxiety. Encephale, 30(1), 1-15.

Mateos, M., Villalon, R., De Dios, M. J., \& Martin, E. (2007). Reading and writing tasks on different university degree courses: What do the students say they do? Studies in Higher Education, 32(4), 489510.

Milgrim, N., Marshevsky, S., \& Sadeh, C. (1995).Correlates of academic procrastination: Discomfort, task evasiveness, and task capability. The Journal of Psychology, 129, 145-147.

Moon, S. M., \& Illingworth, A. J. (2005). Exploring the dynamic nature of procrastination. Personality and Individual Differences, 38(2), 297-309.

Novak, J. D. (2002). Meaningful learning: The essential factor for conceptual change in limited or inappropriate propositional hierarchies leading to empowerment of learners. Science Education, 86(4), 548571

Paludi, M. A., \& Frankell-Hauser, J. (1986). An idiographic approach to the study of women's achievement striving. Psychology of Women Quarterly, 10, 89-100.

Peled, Y., \& Sarid, M. (2010). Meaningful learning through a multi-drafting feedback process in a webbased learning content management environment. IADIS International Conference e-Society 2010. Retrieved May 11, 2010, from http://www.iadis.net/d1/Search_list_open.asp?code $=6875$

Rothblum, E. D., Solomon, L. J., \& Murakami, J. (1986). Affective, cognitive, and behavioral differences between high and low procrastinators. Journal of Counseling Psychology, 33, 387-394.

Russell, T. (1994) Effective feedback skills. London: Kogan Page

Samarawickrema, G., \& Stacey, E. (2007). Adopting web-based learning and teaching: A case study in higher education. Distance Education, 28(3), 313-333

Schroeder, K. (2002). College procrastinators. The Education Digest, 67(5), 73-75

Solomon, L. J., \& Rothblum, E. D. (1984). Academic procrastination: Frequency and cognitive-behavioral correlates. Journal of Counseling Psychology, 31, 503-509.

Spielberger, C. D. (1983). Manual for the State-Trait Anxiety Inventory (STAI). Palo Alto, CA: Consulting Psychologists Press.

Spielberger, C. D., Gorsuch, R. L., \& Lushene, R. E. (1968). STAI Manual. Palo Alto, CA: Consulting Psychologists Press.

Thomson, K., \& Falchikov, N. (1998). "Full on until the sun comes out": The effects of assessment on student approaches to learning. Assessment \& Evaluation in Higher Education, 23(4), 379-390.

Tice, D. M., Bratslavsky, E., \& Baumeister, R. F. (2001). Emotional distress regulation takes precedence over impulse control: If you feel bad, do it! Journal of Personality and Social Psychology, 80, 53-67.

Tuckman, B. (1991). The development and concurrent validity of the procrastination scale. Educational and Psychological Measurement, 51, 473-480.

Uzun Özer, B., Demir, A., \& Ferrari, J. (2009). Exploring academic procrastination among Turkish students: Possible gender differences in prevalence and reasons. The Journal of Social Psychology, $149(2), 241-257$. 
Van Eerde, W. (2003). Procrastination at work and time management training. Journal of Psychology, 137, 421- 435.

Wiedmer. T. L. (1998). Digital portfolios. Phi Delta Kappan, 79(8), 586-590.

Winnips, K. (2000) Scaffolding by Design: A model for WWW-based learner support. (Doctoral Dissertation, Faculty of Educational Science and Technology, University of Twente).

Yang, Y. (2006). Feedback on College EFL Students' Compositions. US-China Foreign Language, 4(11), 93-96

Yu, F. Y., Liu, Y. H., \& Chan, T. W. (2005). A web-based learning system for question-posing and peer assessment. Innovations in Education and Teaching International, 42(4), 337-348

\section{Biographies}

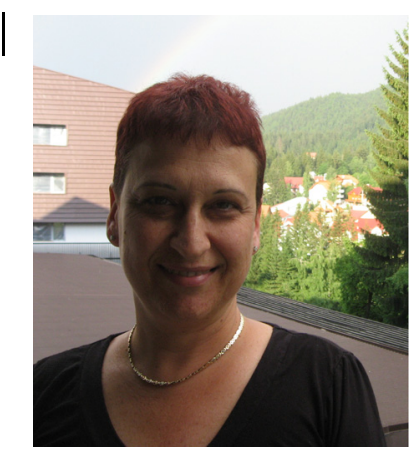

Miri Sarid is a member of education department and inter-disciplinary department in the Western Galilee Academic College, and academic manager of empowering women in economics and management program at the college, P.O.B. 2125 Acre 24121 Israel. She is also a statistical consultant and joint owner in "Sarid institute for research services and consulting", Kiryat Haim, Israel. email: miris@wgalil.ac.il

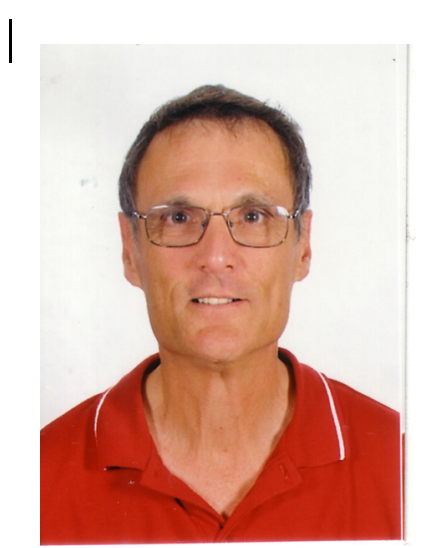

Yehuda Peled is the head of the information studies department at the Western Galilee College P.O.B. 2125 Acre 24121 Israel and a member of the science and environment department at the Ohalo teacher Training academic College P.O.B. 222 Katzrin 129000 Israel. Email:

ypeled@macam.ac.il 